\title{
A Study on the Relationship between Emotional Intelligence and Stress Handling Methods of Dental Hygiene
}

\author{
Hwa-Kyung Son, Jin-Young Choi \\ Department of Dental Hygiene, Yeungnam University College, Daegu, Korea
}

Objective: The purpose of this study was to analyze the association between emotional intelligence and stress handling in dental hygienists and develop strategies to relieve job stress and cope with stress efficiently.

Methods: 170 dental hygienists currently working at dental hospitals and clinics in Daegu and North Gyeongsang Province participated in this study. WLEIS and the stress handling scale were used to analyze their general and work-related characteristics and emotional intelligence.

Results: The older, the more educated, and the higher position, the higher emotional intelligence; the administrators had higher emotional intelligence than those in charge of prevention; and those more intimate with other members had significantly higher emotional intelligence. The more educated and the more intimate with other members, the more likely to use a stress handling method. Stress handling methods were significantly positively correlated with emotional intelligence in general; problem-based and social support-pursuing handling methods among the sub-areas of stress handling methods were significantly positively correlated with emotional intelligence.

Conclusion: It is necessary to apply a program that can improve emotional intelligence in managing stress for dental hygienists; stress handling and hospital personnel management schemes can be used by running an emotional intelligence improvement program on a regular basis in clinical practice.

Keywords: emotional intelligence, stress, response, dental hygienists

\section{Introduction}

The increase in life expectancy with the improvement in medical technology has made people pay more attention to a

\section{Corresponding author Jin-Young Choi}

E-mail: cjysky21@naver.com

(iD) https://orcid.org/0000-0001-6439-4932

Received September 5, 2021, Revised September 27, 2021 , Accepted September 30, 2021 healthy life and healthcare consumers seek high-quality healthcare service [1]. The area of oral health, which is a part of healthcare service, is more specialized and segmented than before; such problems as heavy workload due to the drastic increase in the demand for healthcare service, the increased healthcare disputes, and increasing competition among hospitals cause a lot of stress for healthcare providers [2]. Dental hygienists with a lot of personal contacts with patients are more exposed to stress due to the characteristics of their work [3]. It has been reported that stress experienced by hospital

Copyright (C) 2021. Korean Academy of Preventive Dentistry. All rights reserved.

This is an Open Access article distributed under the terms of the Creative Commons Attribution Non-Commercial License (http://creativecommons.org/licenses/ by-nc/4.0) which permits unrestricted non-commercial use, distribution, and reproduction in any medium, provided the original work is properly cited. 
employees can affect service providers in many different ways in relation to healthcare service provision and ultimately affect the quality of healthcare service for patients [4]. However, how individuals use their own inner resources and ability to perceive and cope with stress is more important than stress itself [5]. A stress handling method refers to an act of minimizing damages from any stressor and doing something to get rid of stress or a positive process of confronting any crisis and helps adapt to a stressful situation [5]. Recently, it is indicated that emotional intelligence plays a crucial role in controlling emotions caused by stress [6]. Emotional intelligence refers to an ability to understand one's own emotions and those of others, control them, and use known emotions efficiently in many different situations [7]. It is reported that people with high emotional intelligence show an effective method of handling a given stressful situation by evaluating it positively and trying to solve any problem actively [8], whereas those with low emotional intelligence can experience emotional conflicts and are more likely to perceive stress [9]. It can be said that the attempt to improve emotional intelligence and use an effective stress handling method is essential for clinical dental hygienists to adapt themselves to clinical practice. While some researchers have confirmed that emotional intelligence can reduce academic and job stress and is an important variable of organizational effectiveness and emotional labor in college students and nurses, extremely little research has been conducted in dental hygienists. In addition, how to accept a given stressful situation is more important than stress itself [10], and an effective stress handling method can help manage stressors and change any possible adverse result into positive one [11]. This study aimed to provide basic data that could help develop strategies to relieve job stress and cope with stress efficiently.

\section{Materials and Methods}

\section{Subjects}

The research was conducted in dental hygienists currently working at clinics and hospitals in Daegu and North Gyeongsang Province, who were given full explanation as to the purpose and contents of the study, understood them, and consented to participate spontaneously in the study. The minimum sample size necessary for correlation analysis was estimated through a $G$ power 3.1 program to be 164 persons with the significance level 0.05 and the effect size 0.90 , and 180 questionnaires were distributed, taking into account the possibility of making an inappropriate response and the dropout rate. The data from a total of 170 copies were analyzed, with the exception of 9 incorrectly completed or incomplete ones.
Table 1. General characteristics a of the study subjects $(\mathrm{N}=170)$

\begin{tabular}{|c|c|c|}
\hline Characteristics & $\mathrm{N}(\%)$ & $M \pm S D$ \\
\hline \multicolumn{3}{|l|}{ Age } \\
\hline 21-25 & $112(65.9)$ & $28.4 \pm 6.52$ \\
\hline $26-30$ & $26(15.3)$ & \\
\hline $31-40$ & $23(13.5)$ & \\
\hline$\geq 41$ & $9(5.3)$ & \\
\hline \multicolumn{3}{|l|}{ Work career year (month) } \\
\hline 2 year $<$ (24 month $)$ & $75(44.1)$ & $79.54 \pm 74.55$ \\
\hline 2-5 year (24-60 month) & $14(8.2)$ & \\
\hline 5-10 year (60-120 month) & $17(10.0)$ & \\
\hline $10-20$ year (120-240 month) & $14(8.2)$ & \\
\hline$\geq 20$ year (240 month) & $50(29.4)$ & \\
\hline \multicolumn{3}{|l|}{ Marital status } \\
\hline Single & $122(71.8)$ & \\
\hline Married & $48(28.2)$ & \\
\hline \multicolumn{3}{|l|}{ Education } \\
\hline College & $115(67.6)$ & \\
\hline University & $31(18.2)$ & \\
\hline Graduate school & $24(14.1)$ & \\
\hline \multicolumn{3}{|l|}{ Service hospital } \\
\hline Dental office & $117(68.6)$ & \\
\hline Dental Clinic & $44(25.9)$ & \\
\hline General hospital & $4(2.4)$ & \\
\hline Other & $5(2.9)$ & \\
\hline \multicolumn{3}{|l|}{ Position } \\
\hline Team member & $117(68.6)$ & \\
\hline Team leader & $18(10.6)$ & \\
\hline Head of department & $31(18.2)$ & \\
\hline Manager (higher rank than director) & $9(5.3)$ & \\
\hline \multicolumn{3}{|l|}{ Major type of work } \\
\hline Treatment assistants & $128(75.3)$ & \\
\hline Prevention work & $6(3.5)$ & \\
\hline Counseling & $19(11.2)$ & \\
\hline Administrative & $9(5.3)$ & \\
\hline Other & $8(4.7)$ & \\
\hline \multicolumn{3}{|l|}{ Wage } \\
\hline$<150$ & $5(2.9)$ & \\
\hline $150-200$ & $71(41.8)$ & \\
\hline $200-250$ & $50(29.4)$ & \\
\hline$\geq 250$ & $44(25.9)$ & \\
\hline \multicolumn{3}{|l|}{ Number of employees (people) } \\
\hline $1-4$ & $50(29.4)$ & \\
\hline $5-9$ & $53(31.2)$ & \\
\hline $10-19$ & $25(14.7)$ & \\
\hline$\geq 20$ & $42(24.7)$ & \\
\hline \multicolumn{3}{|l|}{ Intimacy } \\
\hline Not familiar at all & $3(1.8)$ & \\
\hline Somewhat familiar & $46(27.1)$ & \\
\hline Familiar & $86(50.6)$ & \\
\hline Very familiar & 35 (20.6) & \\
\hline \multicolumn{3}{|l|}{ Work intensity } \\
\hline Very low & $2(1.2)$ & \\
\hline Somewhat low & $7(4.1)$ & \\
\hline Average & $66(38.8)$ & \\
\hline Somewhat high & $64(37.6)$ & \\
\hline Very high & $31(18.2)$ & \\
\hline
\end{tabular}




\section{Instruments}

Eight items concerning the general and job-related characteristics came from Jung [12]'s translation of the Wong and Law Emotional Intelligence Scale (WLEIS), an emotional intelligence scale that had been developed by Wong and Law [7] and is applicable to many different organizations. It is composed of 16 items -4 in each area of the understanding of one's own emotions, the understanding of others' emotions, emotional regulation, and emotion utilization - with a higher score meaning higher emotional intelligence.

The stress handling method inventory, which had been developed by Folkman and Lazarus [5], translated and revised through factor analysis by Kim and Lee [13], and adapted to have 24 items by Park [14], was used to measure stress handling methods. It is composed of 24 items, 6 in each of four areas - problem-based handling, handling through pursuit of social support, emotion-based handling, and handling through wishful thinking-with a higher score meaning more likeliness to use a stress handling method in the given area. For reliability, Cronbach's $\alpha$ was estimated at 0.727 for emotional intelligence and at 0.657 for stress handling methods.

\section{Statistical Analysis}

An SPSS Statistics 26.0 Network Version (on release 26.0 of PASW Statistics) program was used for analyses. Frequency analysis, descriptive statistics, t-test, ANOVA, and Pearson's correlation coefficient were used.

\section{Results}

\section{Respondents' general and job-related characteristics}

Respondents' general and job-related characteristics are as follows (Table 1):
The mean age was $28.4 \pm 6.52$ years, and 67 respondents (36.6\%) were aged $25-29.122$ respondents $(71.8 \%)$ were unmarried; $115(67.6 \%)$ were college graduates. 117 respondents $(68.8 \%)$ were employed at dental clinics, 44 (25.9\%) at dental hospitals, $5(2.9 \%)$ at others, and $4(2.4 \%)$ at general hospitals. 112 respondents $(65.9 \%)$ were general dental hygienists; the mean career was $79.54 \pm 74.55$ months, with $75(44.1 \%)$ having $<2$ years of career. As for a major type of work, 128 respondents $(75.3 \%)$ were treatment assistants. 71 respondents (41.8\%) earned 1.5 million to less than 2 million won. The most frequent number of employees was 5-9 (53; $31.2 \%)$, followed by $1-4(50 ; 29.4 \%), \geq 20(42 ; 24.7 \%)$, and $10-19(25 ; 14.7 \%)$. The most frequent degree of familiarity with other members of the clinic was 'familiar' $(86 ; 50.6 \%)$, followed by 'somewhat familiar' $(46 ; 27.1 \%)$, 'very familiar' $(35 ; 20.6 \%)$, 'not familiar at all' $(3 ; 1.8 \%)$. The most frequent intensity of work was 'average' $(66 ; 38.8 \%)$, followed by 'somewhat high' (64; 37.6\%), 'very high' (31; 18.2\%), 'somewhat low' (7; 4.1\%), and 'very low' $(2 ; 1.2 \%)$.

\section{Respondents' emotional intelligence and stress handling methods}

The results for the respondents' emotional intelligence and stress handling methods are as follows (Table 2):

They scored an average of $3.00 \pm 0.77$ out of 7 for emotional intelligence; as for its sub-areas, they scored an average of $3.77 \pm 1.19$ for use of emotion, $3.20 \pm 1.13$ for the emotional regulation, $2.59 \pm 0.92$ for the Others' emotion appraisal, and $2.44 \pm 0.88$ for the self-emotion appraisal. They scored an average of $2.49 \pm 0.34$ out of 4 for stress handling methods; as for its sub-areas, they scored an average of $2.88 \pm 0.48$ for Emotional Response, $2.47 \pm 0.52$ for Problem-driven response, $2.39 \pm 0.52$ for Addressing the pursuit of social support, and $2.20 \pm 0.49$ for coping with wishful thinking.

Table 2. Emotional Intelligence and Stress Response Score

\begin{tabular}{|c|c|c|c|c|c|}
\hline Variable & Characteristics & $M \pm S D$ & Minimum v & mum value & Range \\
\hline \multirow[t]{5}{*}{ Emotional intelligence } & Self-emotion appraisal & $2.44 \pm 0.88$ & 1.00 & 5.50 & \multirow[t]{5}{*}{$1-7$} \\
\hline & Others' emotion appraisal & $2.59 \pm 0.92$ & 1.00 & 6.50 & \\
\hline & Regulation of emotion & $3.20 \pm 1.13$ & 1.00 & 6.25 & \\
\hline & Use of emotion & $3.77 \pm 1.19$ & 1.00 & 7.00 & \\
\hline & Emotional Intelligence (AII) & $3.00 \pm 0.77$ & 1.25 & 5.75 & \\
\hline \multirow[t]{5}{*}{ Stress response method } & Problem-driven response & $2.47 \pm 0.52$ & 1.33 & 4.00 & \multirow[t]{5}{*}{$1-4$} \\
\hline & Addressing the pursuit of social support & $2.39 \pm 0.52$ & 1.33 & 4.00 & \\
\hline & Emotional Response & $2.88 \pm 0.48$ & 1.00 & 4.00 & \\
\hline & Coping with wishful thinking & $2.20 \pm 0.49$ & 1.00 & 3.50 & \\
\hline & Stress response (All) & $2.49 \pm 0.34$ & 1.71 & 3.50 & \\
\hline
\end{tabular}




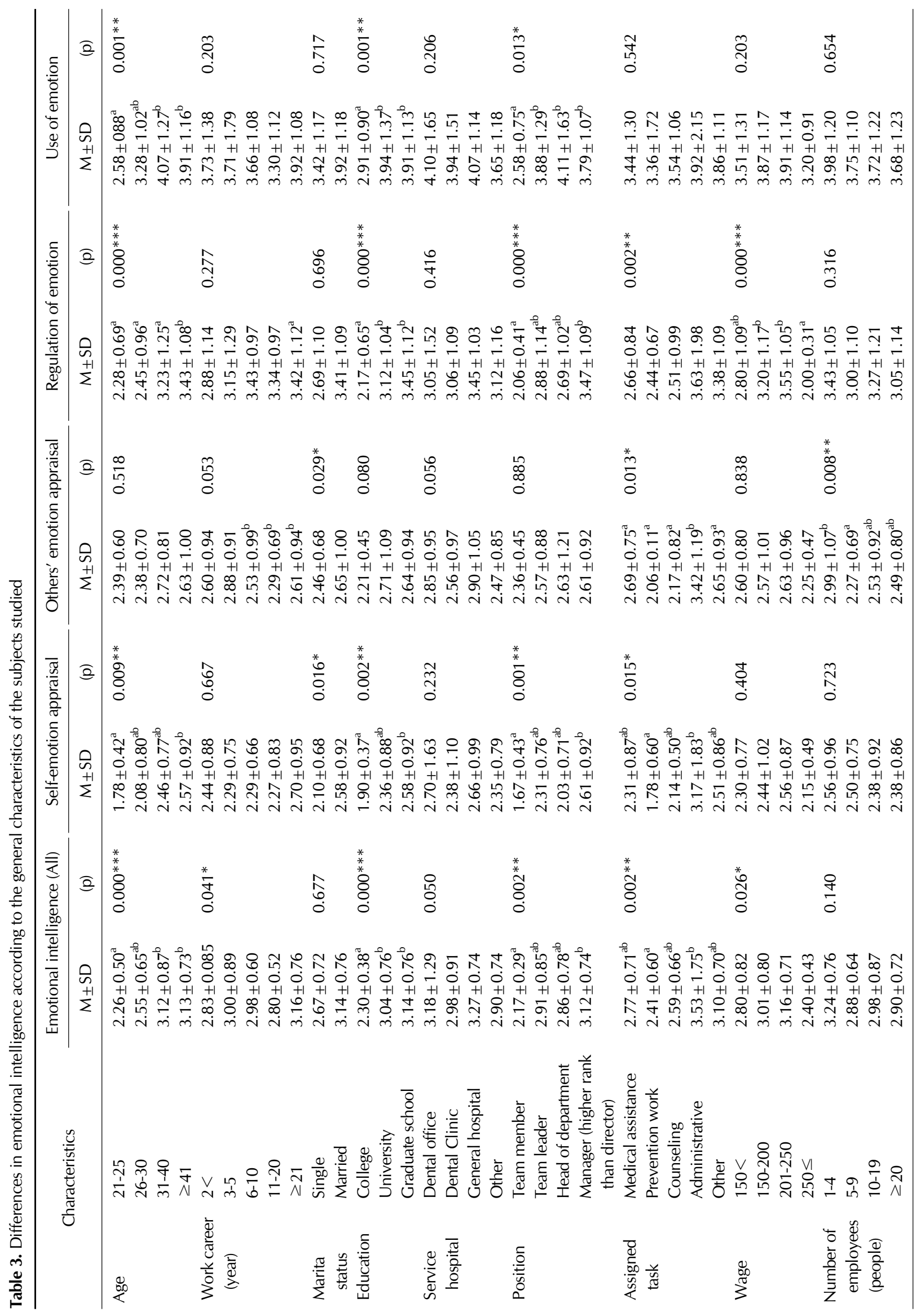




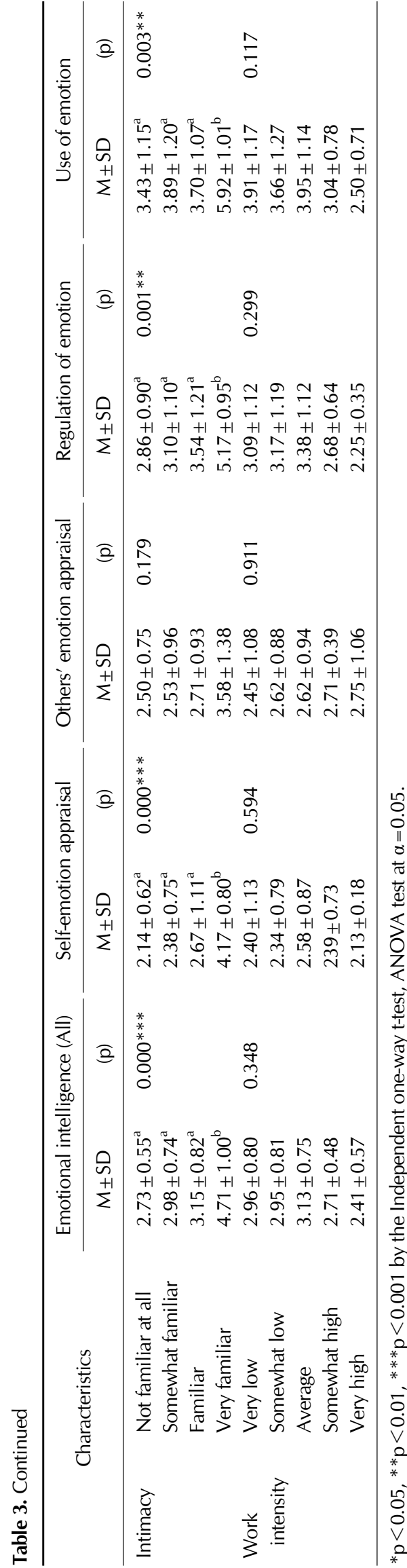

\section{Variation in emotional intelligence by general characteristics}

The test for variation in emotional intelligence by the general and job-related characteristics obtained the following results (Table 3): Emotional intelligence differed significantly by age $(p=0.000)$, Work career $(p=0.041)$, education $(p=$ $0.000)$, position $(p=0.002)$, work $(p=0.002)$, wage $(p=0.026)$, and intimacy $(p=0.000)$. The posttest found that the older, the more educated, and the higher position, the higher emotional intelligence; the administrators had higher emotional intelligence than those in charge of prevention; and those more intimate with other members had significantly higher emotional intelligence.

Among the sub-areas of emotional intelligence, the 'selfemotion appraisal' differed significantly by age $(p=0.009)$, marital status $(\mathrm{p}=0.016)$, education $(\mathrm{p}=0.002)$, position $(\mathrm{p}=$ $0.001)$, work $(\mathrm{p}=0.015)$, and intimacy $(\mathrm{p}=0.000)$. The 'Others' emotion appraisal' differed significantly by marital status $(p=0.029)$, work $(p=0.013)$, and the number of employees $(p=0.008)$. The 'regulation of emotion' differed significantly by age $(p=0.000)$, education $(p=0.000)$, position $(p=0.000)$, work $(p=0.002)$, wage $(p=0.000)$, and intimacy $(p=0.001)$. The 'use of emotion' differed significantly by age $(\mathrm{p}=0.001)$, education $(\mathrm{p}=0.001)$, position $(\mathrm{p}=0.013)$, and intimacy $(\mathrm{p}=$ $0.003)$.

\section{Variation in stress handling methods by general characteristics}

The test for variation in stress handling methods by the general and job-related characteristics obtained the following results (Table 4): Stress handling methods differed significantly by education $(p=0.001)$ and intimacy $(p=0.009)$. The posttest found that the more educated and the more intimate with other members, the more likely to use a stress handling method. Among the sub-areas of stress handling methods, 'Problemdriven response' differed significantly by age $(p=0.000)$, career $(p=0.016)$, education $(p=0.000)$, position $(p=0.002)$, work $(p=0.002)$, wage $(p=0.000)$, and intimacy $(p=0.000)$. The posttest found that the older, the more educated, the longer career, the higher wage, and the more intimate with other members, the more likely to use a problem-based handling method. 'Addressing the pursuit of social support' differed significantly by education $(\mathrm{p}=0.020)$, intimacy $(\mathrm{p}=0.001)$, and work intensity $(p=0.026)$. The posttest found that the more educated, the more likely to use the method of handling through pursuit of social support and that the more intimate with other members and the more intense work, the more likely to use the method of handling through pursuit of social 


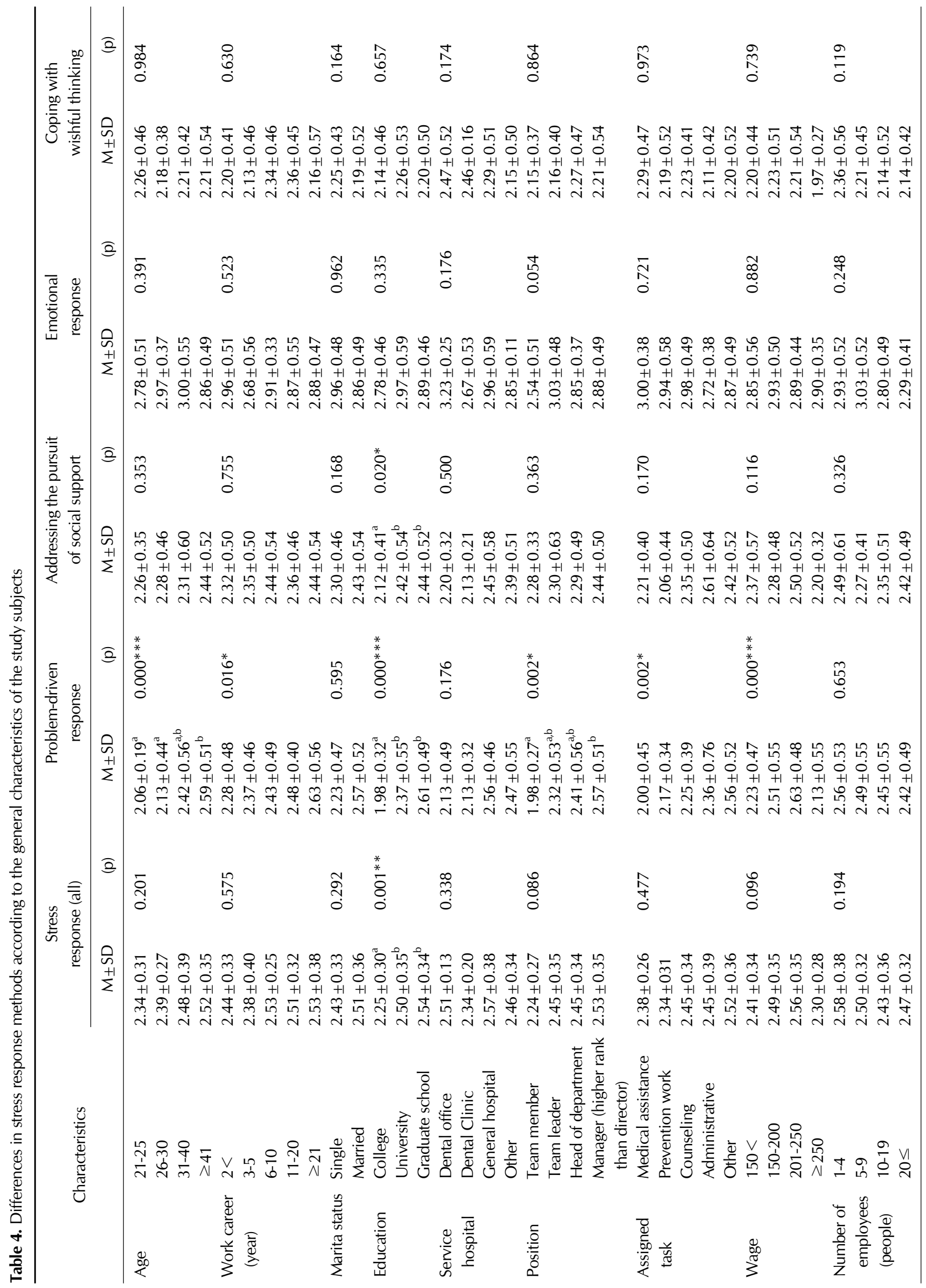

90 Vol. 17, No. 3, September 2021 


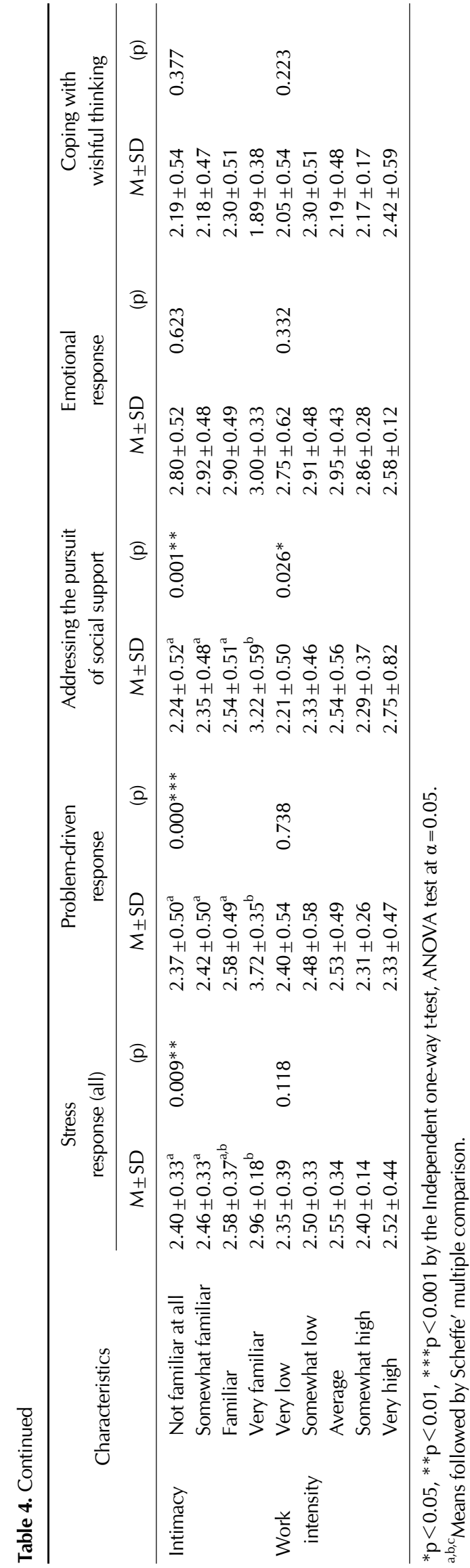

support. Neither 'Emotional Response' nor 'coping with wishful thinking' differed by any general characteristic.

\section{Correlation between emotional intelligence and stress handling methods}

Stress handling methods were significantly positively correlated with emotional intelligence in general $(\mathrm{r}=0.438$, $\mathrm{p}<0.01)$; Problem-driven response $(\mathrm{r}=0.535, \mathrm{p}<0.01)$ and Addressing the pursuit of social support $(r=0.401, p<0.01)$ among the sub-areas of stress handling methods were significantly positively correlated with emotional intelligence (Table 5).

\section{Discussion}

This study aimed to analyze the association between emotional intelligence and stress handling in dental hygienists and develop strategies to relieve job stress and cope with stress efficiently.

They scored an average of $3.00 \pm 0.77$ out of 7 for emotional intelligence: specifically, $3.77 \pm 1.19$ for the regulation of emotion, $3.20 \pm 1.13$ for the use of emotion, $2.59 \pm 0.92$ for the Others' emotion appraisal, and $2.44 \pm 0.88$ for the self-emotion appraisal. Similarly, Kim [15] found that the dental hygienists scored $3.41 \pm 0.29$ out of 7 for emotional intelligence and that the older and the more educated, the higher emotional intelligence. Park et al. [16], who conducted research by using the same instrument, found that the nurses scored relatively high for emotional intelligence (4.9)-specifically, 5.1 for the Others' emotion appraisal, 5.0 for the self-emotion appraisal, 4.8 for the regulation of emotion, and 4.6 for the use of emotion-unlike this study; Cho et al. [17] found that the nurses who were married, older, and more educated and had longer career had higher emotional intelligence, consistent with this study. These results demonstrate that those who were older and more educated may have interpersonal relationships based on more diverse experiences, cope comfortably with many different treatment situations, and, consequently, have higher emotional intelligence.

The score for stress handling methods was $2.49 \pm 0.34$ out of 4 and was lower than 3.31 in Ghang and Kim [18], who conducted research in nurses at mental hospitals, and was similar to 2.4 in Park et al. [16] and Kang and Kim [18], who conducted research in nurses. Among the sub-areas of stress handling, they scored $2.88 \pm 0.48$ for the Emotional Response, $2.47 \pm 0.52$ for the Problem-driven response, $2.39 \pm 0.52$ for the Addressing the pursuit of social support, and 2.20 \pm 0.49 for the coping with wishful thinking, which differs from the finding of prior studies in nurses $[16,18]$ that they were most likely to 
Table 5. Correlation between Emotional Intelligence and Stress Response of Subjects

\begin{tabular}{|c|c|c|c|c|c|c|c|c|c|c|}
\hline & $\begin{array}{l}\text { Self-emotion } \\
\text { appraisal }\end{array}$ & $\begin{array}{l}\text { Others' } \\
\text { emotion } \\
\text { appraisal }\end{array}$ & $\begin{array}{l}\text { Regulation } \\
\text { of emotion }\end{array}$ & $\begin{array}{c}\text { Use of } \\
\text { emotion }\end{array}$ & $\begin{array}{c}\text { Problem- } \\
\text { driven } \\
\text { response }\end{array}$ & $\begin{array}{c}\text { Addressing } \\
\text { the pursuit } \\
\text { of social } \\
\text { support }\end{array}$ & $\begin{array}{l}\text { Emotional } \\
\text { response }\end{array}$ & $\begin{array}{l}\text { Coping } \\
\text { with } \\
\text { wishful } \\
\text { thinking }\end{array}$ & $\begin{array}{l}\text { Emotional } \\
\text { Intelligence } \\
\text { (All) }\end{array}$ & $\begin{array}{c}\text { Stress } \\
\text { Response } \\
\text { (All) }\end{array}$ \\
\hline Elf-emotion appraisal & 1 & & & & & & & & & \\
\hline $\begin{array}{l}\text { Others' emotion } \\
\text { appraisal }\end{array}$ & $0.466^{* *}$ & 1 & & & & & & & & \\
\hline Regulation of emotion & $0.469 * *$ & $0.421 * *$ & 1 & & & & & & & \\
\hline Use of emotion & $0.299 * *$ & $0.313^{* *}$ & $0.483^{* *}$ & 1 & & & & & & \\
\hline $\begin{array}{l}\text { Problem-driven } \\
\text { response }\end{array}$ & $0.361^{* *}$ & $0.210^{* *}$ & $0.607^{* *}$ & $0.377^{* *}$ & 1 & & & & & \\
\hline $\begin{array}{l}\text { Addressing the pursuit } \\
\text { of social support }\end{array}$ & $0.349 * *$ & $0.331 * *$ & $0.403 * *$ & 0.141 & $0.499 * *$ & 1 & & & & \\
\hline Emotional Response & 0.098 & -0.033 & 0.135 & 0.121 & $0.190^{*}$ & $0.175^{*}$ & 1 & & & \\
\hline $\begin{array}{l}\text { Coping with wishful } \\
\text { thinking }\end{array}$ & 0.137 & $0.192^{*}$ & $0.187^{*}$ & -0.085 & $0.211^{* *}$ & $0.348^{* *}$ & $0.340 * *$ & 1 & & \\
\hline $\begin{array}{l}\text { Emotional } \\
\text { Intelligence (AIl) }\end{array}$ & $0.713 * *$ & $0.707^{* *}$ & $0.814 * *$ & $0.742 * *$ & $0.535^{* *}$ & $0.401 * *$ & 0.114 & 0.132 & 1 & \\
\hline Stress Response (AII) & $0.350 * *$ & 0.260 & $0.493^{* *}$ & $0.207^{* *}$ & $0.705^{* *}$ & $0.747^{* *}$ & $0.606 * *$ & $0.685^{* *}$ & $0.438^{* *}$ & 1 \\
\hline
\end{tabular}

${ }^{*} \mathrm{p}<0.05,{ }^{* *} \mathrm{p}<0.01$ by the Pearson's correlation coefficient.

use problem-based handling. As for variation in the sub-areas of stress handling methods by the general characteristics, the older, the more educated, the longer career, the higher wage, and the more intimate with other members, the more likely to use a problem-based handling method. This result was consistent with prior studies in nurses $[16,18]$. This implies the roles of experienced dental hygienists: the style of getting more familiar with other members and trying to solve problems properly in a tough situation differs between novice and experienced dental hygienists. Therefore, further research should be conducted to confirm this result.

Stress handling methods were significantly positively correlated with emotional intelligence in general $(r=0.438, p<$ 0.01); Problem-driven response $(\mathrm{r}=0.535, \mathrm{p}<0.01)$ and Addressing the pursuit of social support $(\mathrm{r}=0.401, \mathrm{p}<0.01)$ among the sub-areas of stress handling methods were significantly positively correlated with emotional intelligence. In a stressful situation, people with high emotional intelligence evaluated every issue positively and made efforts to solve it actively [19], and those with low emotional intelligence were more likely to feel emotional conflicts and stress [9]. Because dental hygienists constantly face patients with many different needs, it is necessary to give dental hygienists continuous education as to emotional intelligence for emotional management and control so that they can not only understand their own emotions and those of others but also use the emotions to solve problems in pursuit of positive stress handling; it is also neces- sary to develop a program that allows dental hygienists to cope with stress positively. Dental hygienists' positive stress handling and high emotional intelligence are expected to give high-quality healthcare service and affect organizations positively.

\section{Conclusion}

This study analyzed the data from 170 questionnaires completed by dental hygienists working at dental hospitals and clinics in Daegu and North Gyeongsang Province and drew the following conclusion:

1. They scored an average of $3.00 \pm 0.77$ out of 7 for emotional intelligence; they scored highest for the use of emotion (3.77 \pm 1.19$)$ and lowest for the self-emotion appraisal $(2.44 \pm$ $0.88)$. They scored an average of $2.49 \pm 0.34$ out of 4 for stress handling methods; as for the sub-areas, they scored an average of $2.88 \pm 0.48$ for the Emotional Response, $2.47 \pm 0.52$ for the Problem-driven response, $2.39 \pm 0.52$ for the Addressing the pursuit of social support, and $2.20 \pm 0.49$ for the coping with wishful thinking.

2. The older, the more educated, and the higher position, the higher emotional intelligence; the administrators had higher emotional intelligence than those in charge of prevention; and those more intimate with other members had significantly higher emotional intelligence. The more educated and the more intimate with other members, the more likely to 
use a stress handling method.

3. Stress handling methods were significantly positively correlated with emotional intelligence in general $(\mathrm{r}=0.438$, $\mathrm{p}<0.01)$; Problem-driven response $(\mathrm{r}=0.535, \mathrm{p}<0.01)$ and Addressing the pursuit of social support $(\mathrm{r}=0.401, \mathrm{p}<0.01)$ among the sub-areas of stress handling methods were significantly positively correlated with emotional intelligence.

To put these results together, emotional intelligence was significantly positively correlated with stress handling methods; the higher level of emotional intelligence, the more likely to use Problem-driven response. It is therefore necessary to develop and provide a stress management program that can help dental hygienists relieve stress. Since emotional intelligence can not only directly affect stress but also induce efficient handling with stress and reduce stress, it is necessary to employ a program that can improve emotional intelligence in managing stress for dental hygienists. It is also necessary to use it as a stress handling and hospital personnel management scheme by running an emotional intelligence improvement program on a regular basis in clinical practice.

\section{Conflict of Interest}

No potential conflict of interest relevant to this article was reported.

\section{ORCID}

Hwa-Kyung Son, https://orcid.org/0000-0002-7548-3540

Jin-Young Choi, https://orcid.org/0000-0001-6439-4932

\section{References}

1. Heo SE, Ji JH. Effect of burnout on the relationship between dental hygienist's job stress and turnover. Korean Health Res 2010;36:35-55.

2. Lee HO, JU OJ, KIM YI. An analysis on factors related to the job satisfaction of dental hygienists at J region. J Dent Hyg Sci 2007; 7:65-72.

3. Go YK, Kang KH. A study on the relationship between self-efficacy, collective-efficacy and job stress in the nursing staff. J Acad Nurs Admin 2006;12:276-86.

4. Muldary TW. Burnout among health professionals: manifes- tations and management. Norwalk: Appleton-Century-Crofts; 1983.

5. Folkman S, Lazarus RS. If it changes it must be a process: study of emotion and coping during three stages of a college examination. J Pers Soc Psychol 1985;48:150-70.

6. Song JE, Chae HJ. Differences in stress and stress coping strategies according to emotional intelligence in nursing students. $\mathrm{J}$ Korean Acad Soc Nurs Educ 2014;20:502-12.

7. Wong CS, Law KS. The effects of leader and follower emotional intelligence on performance and attitude: an exploratory study. Leadersh Q 2002;13:243-74.

8. Benson G, Ploeg J, Brown B. A cross-sectional study of emotional intelligence in baccalaureate nursing students. Nurse Educ Today 2010;30:49-53.

9. Gohm CL, Corser GC, Dalsky DJ. Emotional intelligence under stress: useful, unnecessary, or irrelevant? Personal Individ Differ 2005;39:1017-28.

10. Yeon EK. (The) effects of stress coping strategies on subjective well-being among post anesthetic care unit nurses [thesis]. [Seoul]: Hanyang University; 2011.

11. Lazarus RS, Folkman S. Stress, appraisal, and coping. New York: Springer publishing; 1984.

12. Jung HW. An empirical study on the effect of emotional intelligence on organizational effectiveness [thesis]. [Busan]: Pusan National University; 2007.

13. Kim JH, Lee JH. Components of stress response and relationship to depression. Behavi Sci Res 1985;7:127-38.

14. Park CY. A study on the relationship among character type A \& B ego-identity and stress coping [thesis]. [Seoul]: Sookmyung Women's University; 1995.

15. Kim YI. A study on the effect of emotional labor and emotional intelligence of dental hygiene on organizational effectiveness. J Korean Soc Ind Technol 2019;20:390-6.

16. Park HS, Ha JH, Lee MH, Lee HJ. The relationship between emotional intelligence and stress coping of nurses. J Korean Acad Fundam Nurs 2014;21:466-74.

17. Cho HK, Choi YJ, Jeon MK, Jung GH. Factors affecting nursing productivity of clinical nurses: focused on emotional intelligence and burnout. J Korea Contents Assoc 2015;15:307-16.

18. Kang HS, Kim YY. The effect of emotional intelligence, communication skills, and stress handling of psychiatric nurses on their intentions to change jobs. J Korean Soc Ind Technol 2016;17: 141-51.

19. Benson G, Ploeg J, Brown B. A cross-sectional study of emotional intelligence in baccalaureate nursing students. Nurs Educ Today 2010;30:49-53. 